\title{
The Association Between VDR and GC Polymorphisms and Lung Cancer Risk: A Systematic Review and Meta-Analysis
}

\author{
Guang-qing Duan, Xiao Zheng, Wei-kang Li, Wei Zhang, Zhao Li, and Wei Tan
}

Background: Lung cancer is the leading cause of cancer-related deaths worldwide, imposing an enormous economic burden on society. Several studies have identified a link between the genetic polymorphisms in vitamin D pathways and lung cancer risk; however, the results remain inconclusive. The aim of this study was to estimate the effect of polymorphisms in the vitamin D receptor $(V D R)$ and $G C$ genes on lung cancer risk. Methods: Eligible case-control studies published between January 2000 and December 2018 were searched and studied. The pooled odds ratio and its $95 \%$ confidence interval were used to estimate the effect.

Results: Fifteen articles that included 4732 lung cancer patients and 4337 controls were identified for this study. Our results demonstrated that the VDR Bsml polymorphism $(p<0.05)$ and the TC and TT+TC genotypes of the $C d x 2$ polymorphism $(p<0.05)$ were protective factors for avoiding lung cancer incidence, while the $\mathrm{T}$ allele and the TT genotype of Taq1 polymorphism $(p<0.05)$ were risk factors for lung cancer. Ethnicity-based subgroup analyses indicated that the AA genotype of both the Apal and the Bsml polymorphisms decreased lung cancer risk in Asians, while Fokl and Taql polymorphisms increased lung cancer risk in Asians. Subgroup analysis by cancer subtypes showed that certain alleles and genotypic structures of the Bsml, Fokl, Taql, and rs7041 were associated with nonsmall-cell lung cancer risk. Subgroup analysis by smoking status showed that the interaction between the TT genotype of Taql and smoking increased the risk of lung cancer. Subgroup analysis with regard to gender showed that the AA+Aa genotype of Apal decreased lung cancer risk in male patients.

Conclusions: Our results suggest that the $B s m 1$ and $C d x 2$ polymorphisms decreased lung cancer risk, while the Taql polymorphism increased lung cancer risk. Moreover, the AA genotype of the Apal and Bsml variants were protective factors in Asian populations, whereas the Fokl and Taql polymorphisms were risk factors for lung cancer in Asian populations. Future case-control studies with different ethnicities are still needed to generalize these associations.

Keywords: lung cancer, vitamin D, polymorphism, meta-analysis

\section{Introduction}

$\mathbf{L}$ UNG CANCER IS the most common malignant tumor with the highest mortality worldwide (Schwartz and Cote, 2016). It had led to over 1.6 million people dying in 2012, accounting for $19.4 \%$ of the total cancer deaths, and the number is expected to grow up to 3 million by 2035 (Torre et al., 2016). This malignant tumor is characterized by uncontrolled cell growth in lung tissues, which can spread beyond the lung by the process of metastasis and grow into the tissue surrounding the tumor or to other parts of the body. According to the World Health Organization (WHO), lung cancer is classified into two broad histological subtypes: nonsmall-cell lung cancer (NSCLC), accounting for $85 \%$ of all cases, and small-cell lung cancer (SCLC), accounting for $15 \%$ of all cases (Travis et al., 2015).

NSCLC is further divided into adenocarcinoma, squamous, and large cell carcinoma. There will be an estimated 228,150 new cases diagnosed and 142,670 deaths in the United States in 2019 based on the latest Cancer statistics (Siegel et al., 2019). Its common symptoms include coughing (including coughing up blood), weight loss, shortness of breath, and chest pains (Dougall, 2019). Genetic factors (gene mutations, over- or down-expression) and environmental factors (tobacco use, radon exposure, and indoor and outdoor air pollution) are responsible for the increase of lung cancer incidence (Malhotra et al., 2016; Mao et al., 2016; Duruisseaux and Esteller, 2018).

Postgraduate Department of Internal Medicine, Weifang Medical University, Weifang, China. 
During the past two decades, although the improvements in diagnosis and treatment have been made, challenges still remain: the prognosis for patients with lung cancer is still unsatisfactory, this disease is often diagnosed in the end stage, with poor prognoses; for all stages combined, the 5year relative survival rate is only $15 \%$; a large portion of patients are still treated with conventional chemotherapy that is modestly effective (Esposito et al., 2010; Vijayvergia et al., 2015; Koinis et al., 2016). In the meantime, the primary or secondary resistance to the targeted drug treatment eventually leads to treatment failure in the patients with advanced disease (Lemjabbar-Alaoui et al., 2015). Therefore, development and identification of promising biomarkers could provide new possibilities to enhance early detection and help in making treatment decisions and clinical management.

Genome-wide association studies have identified genetic factors whose epigenetic alterations are robustly involved in the lung cancer development (Bossé and Amos, 2018). Recent studies have revealed that vitamin D may play an important role in the prevention and treatment of many diseases (Jeon and Shin, 2018). The active form of vitamin D exerts their beneficial effects on the body by regulating calcium homeostasis and modulating a large set of gene expression involved in the differentiation and functions of virtually every tissue (DeLuca, 2012). The vitamin D receptor (VDR; OMIM 601769) and the vitamin D-binding protein (DBP; OMIM 124097) are key proteins in vitamin D metabolism. The VDR gene, located on the human chromosome 12 (12q12-14), is a member of the nuclear receptor superfamily of transcriptional regulators and is expressed in most of the human tissues (Carlberg and Campbell, 2013).

VDR regulates the expression of several genes involving in diverse biological functions such as organ development, cell cycle control, calcium and phosphate homeostasis in bone metabolism, and xenobiotic detoxification (Haussler et al., 2013); and it plays multiple roles in both innate and adaptive immune system (Carlberg et al., 2012). VDR is widely expressed in the various tissues, but may vary depending on the developmental stages of the organism and, therefore, may differentially influence phenotypic function that is likely shaped by environment, genetics, and epigenetics (Goltzman et al., 2015).

Experimental studies have observed that higher VDR expression in lung tumors is associated with improved survival (Kim et al., 2012). Gene polymorphisms of VDR have modest and subtle but true biological effects on VDR protein functions. The most commonly studied $V D R$ polymorphisms include Apal (rs7975232, C/A in the intron between exon VII and IX), Bsml (rs1544410, A/G in the intron between exon VII and IX), Fokl (rs2228570, T/C in exon II), Taq1 (rs731236, T/C in exon IX), and $C d x 2$ (11568820, C/T in the promoter region). Genetic variants of $V D R$ might serve as prognostic markers for NSCLC in Chinese population (Liu et al., 2011).

GC, also known as DBP, is a member of the albuminoid superfamily. It is a multifunctional glycoprotein that mainly involves in the binding, solubilization, and transport of vitamin D and its metabolites (Laing and Cooke, 2005). GC functions as a scavenger of extracellular G-actin that increases neutrophil chemotaxis and macrophage activation to modulate certain immune and inflammatory responses (Delanghe et al., 2015). GC gene is located on chromosome 4 and is composed of 13 exons (Cooke et al., 1986). It has a similar structure with the albumin, which is a receptor for active vitamin D3 (Bouillon and Pauwels, 2018). A positive correlation is found between the serum DBP concentration and the 1,25(OH)2-vitamin D3 expression level. $G C$ is highly polymorphic, and the major circulating $G C$ alleles are defined by the genetic polymorphisms rs7041 Asp432Glu and rs4588 Thr436Lys in exon 11. The polymorphisms of $G C$ gene alter the amino acid sequence of the encoded protein and change the protein function, which may influence the binding affinities with $25(\mathrm{OH}) \mathrm{D}$ and affect the plasma concentrations of 25(OH)D (Sinotte et al., 2008) and, thus, influence the vitamin D metabolism in lung cancer risk (Fu et al., 2016).

Although there have been few reports about the association between $V D R$ and $G C$ polymorphisms and lung cancer risk, the results remain inconclusive. For example, Fu et al. (2014) showed that the VDR Bsml polymorphism played a protective role in the lung carcinogenesis, while Zhong et al. (2014) found that B allele and bb genotype were associated with lung cancer risk in overall populations. Furthermore, lung cancer rates and trends vary substantially by sex, age, race/ethnicity, socioeconomic status, and geography (de Groot et al., 2018; Lerner et al., 2018). Genetic and environmental factors may also influence the $V D R$ and $G C$ plasma concentrations and functions (Wilson et al., 2015). Therefore, we conducted the present meta-analysis based on all the available articles to obtain a relatively reliable result.

\section{Methods}

\section{Electronic search of eligible studies}

We performed a comprehensive literature search using the online databases of English (PubMed, Web of science, LISTA, and Embase) and Chinese (Wanfang and China National Knowledge Infrastructure) to search and retrieve relevant articles published between January 2000 and December 2018. The Medical Subject Heading (MeSH) terms were: "lung cancer or carcinoma or tumors," "vitamin D or vitamin D pathways," "vitamin D receptor or VDR," "vitamin D binding protein or DBP or GC," “Apa1/rs7975232 or Bsm1/rs 1544410 or Fok1/rs2228570 or Taq1/rs731236 or Cdx2/11568820 or rs7041 or rs4588," and "polymorphism or single nucleotide polymorphism (SNP) or variant." The corresponding Chinese characters were used in the Chinese databases. The references of retrieved articles were manually checked to obtain more data.

\section{Inclusion and exclusion criteria}

Eligible articles must meet the following inclusion criteria: (1) case-control study evaluating the association between $V D R$ or $G C$ polymorphisms and lung cancer susceptibility; (2) the patients were diagnosed by physicians according to the IASLC Lung Cancer Staging Project guidelines (Goldstraw et al., 2007); (3) the controls were age-matched unrelated participants of the same ethnicity with no history of other chronic pulmonary diseases; and (4) the alleles and genotypes for each SNP were available to extract. The exclusion criteria were the following: (1) without the control group; (2) with duplicated data; and (3) conference papers, reports, comments, or review articles. 


\section{Quality assessment and data extraction}

Two of our authors first assessed the extracted information from retrieved case-control studies independently. Any inconsistent opinion was solved by discussing with the third author to reach a final consensus. The following information was retrieved: the name of first author, publication year, country, ethnicity, mean age, number of cases and controls, classification of lung cancer, and genotyping methods.

\section{Statistical analyses}

The statistical analyses were carried out using the RevMan 5.3 software. The odds ratio (OR) with $95 \%$ confidence interval (CI) was used to calculate the association between $V D R$ and $G C$ polymorphisms and lung cancer risk. The pooled OR was determined by the $Z$ test with $p$-value $<0.05$, which was considered as statistical significant. For each SNP, the allelic model, homozygous model, heterozygous model, dominant model, and recessive model were examined to evaluate its effect. For subgroup analysis, only the allele and genotype differences from control subjects were analyzed. The between-study heterogeneity was assessed by the $Q$ test and the $I^{2}$ test. When the $p$-value of the $Q$ test was $>0.10$ and $I^{2}$ of the $I^{2}$ test was $<50 \%$, the fixed-effect model was used; otherwise, the random-effect model was used. We conducted a sensitivity analysis by omitting any included case-control study at a time and then recalculated the significance of the results to identify whether our results were substantially influenced by the presence of each individual study. The funnel plot was used to examine the publication bias.

\section{Results}

\section{Main characteristics of included articles}

After the keyword-based searching on databases, we first obtained 113 available case-control studies. Along with the inclusive and exclusive criteria, a total of 15 articles were finally screened out, including 4732 lung cancer patients and 4337 controls. Figure 1 showed the flow diagram of literature search and selection process. The 15 included articles were conducted in 5 countries: Turkey (Dogan et al., 2009; Çiçek et al., 2017), China (Li et al., 2013; Yang et al., 2013, 2017; Liu et al., 2014; Wei et al., 2014; Hou, 2015; Kong et al., 2015; Bi et al., 2016; Wu et al., 2016; Wensheng et al., 2018), Tunisia (Kaabachi et al., 2014), Thailand (Maneechay et al., 2015), and Poland (Gromowski et al., 2017). Seven of the articles were written in English, and 8 were in Chinese; and 11 were performed in Asian populations, and 4 performed in Caucasian populations. Eight articles were conducted in patients with NSCLC and others in mixed lung cancer or not to mention the cancer subtypes. The sample size ranged from 100 to 1760. Five SNPs (Apa1, Bsm1, Fok1, Taq1, Cdx2) of $V D R$ gene and two (rs7041, rs4588) of $G C$ gene were finally identified. The main characteristics of included studies are presented in Table 1.

\section{Association of VDR polymorphisms in lung cancer risk}

Table 2 showed the meta-analysis results of $V D R$ and $G C$ polymorphisms in lung cancer susceptibility in total populations and subgroup analysis by ethnicity.

\section{Apa1}

Ten articles contained 3609 lung cancer patients, and 3099 controls were studied. The statistical analysis showed that Apal polymorphism was not associated with lung cancer risk under any genetic comparison models in total population (A vs. a: $\mathrm{OR}=0.83,95 \% \mathrm{CI}=0.66-1.03, p=0.09$; AA vs. aa: $\mathrm{OR}=0.74,95 \% \quad \mathrm{CI}=0.51-1.07, \quad p=0.11 ;$ Aa vs. aa: $\mathrm{OR}=1.01,95 \% \mathrm{CI}=0.76-1.34, p=0.95 ; \mathrm{AA}+\mathrm{Aa}$ vs. aa: $\mathrm{OR}=0.88,95 \% \mathrm{CI}=0.68-1.14, p=0.34$; AA vs. Aa+aa: $\mathrm{OR}=0.71,95 \% \mathrm{CI}=0.48-1.04, p=0.08)$. Subgroup analysis by ethnicity indicated that only AA genotype in recessive model was correlated with decreased cancer risk in Asians

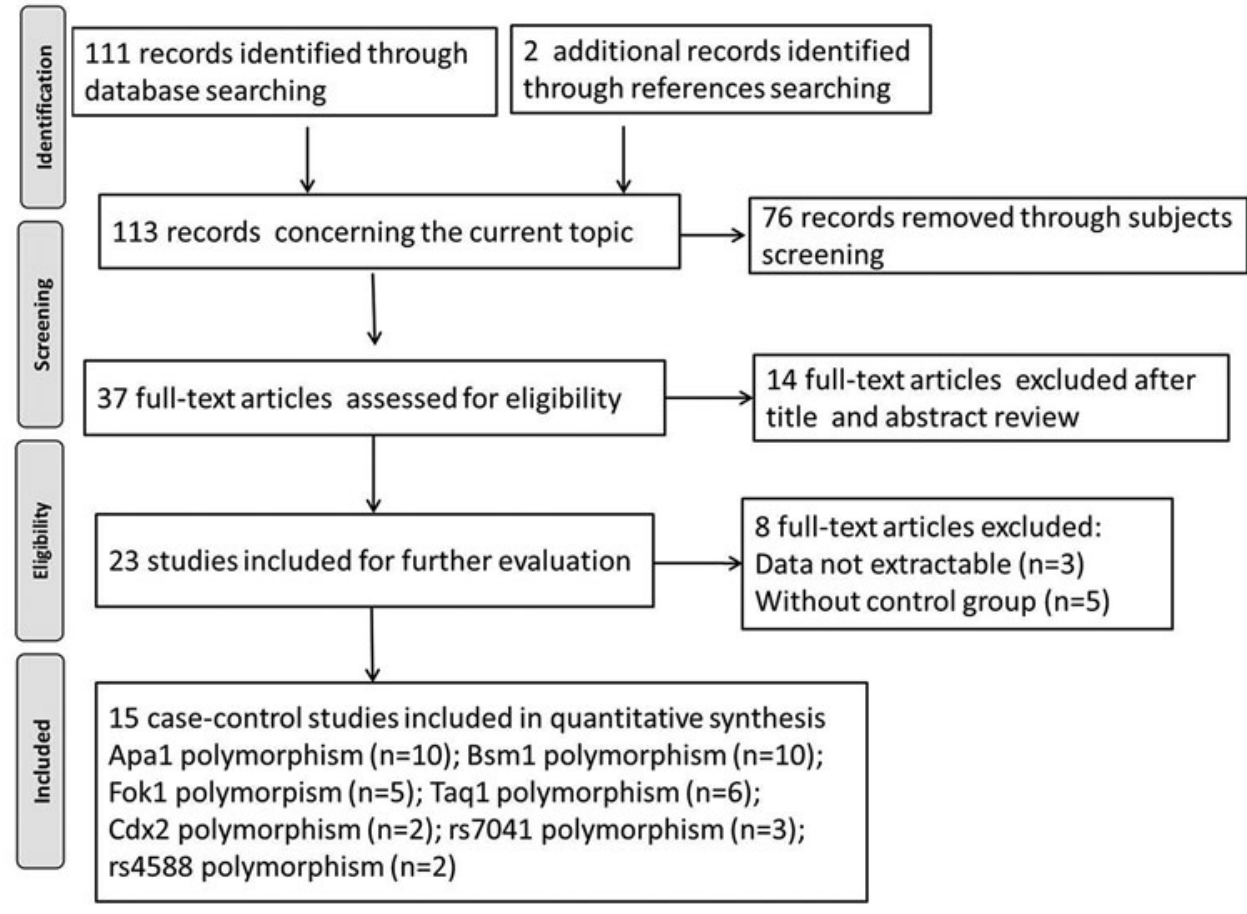

FIG. 1. The flow diagram of the screening process of the case-control studies. 
Table 1. Main Characteristics of the Identified Studies Included in This Meta-Analysis

\begin{tabular}{|c|c|c|c|c|c|c|c|c|c|}
\hline \multirow{2}{*}{$\begin{array}{l}\text { First } \\
\text { author's } \\
\text { name }\end{array}$} & \multirow[b]{2}{*}{ Year } & \multirow[b]{2}{*}{ Country } & \multirow[b]{2}{*}{ Ethnicity } & \multicolumn{2}{|c|}{ Mean age } & \multicolumn{2}{|c|}{ Sample size } & \multirow{2}{*}{$\begin{array}{c}\text { Classification } \\
\text { of disease }\end{array}$} & \multirow{2}{*}{$\begin{array}{l}\text { Genotyping } \\
\text { method }\end{array}$} \\
\hline & & & & Cases & Controls & Cases & Controls & & \\
\hline Dogan & 2009 & Turkey & Caucasians & Mixed & Mixed & 137 & 156 & Mixed & PCR-RFLP \\
\hline $\mathrm{Li}$ & 2013 & China & Asians & $58 \pm 10$ & $55 \pm 15$ & 72 & 67 & Mixed & PCR-sequencing \\
\hline Yang & 2013 & China & Asians & $65.4(57-70)$ & $66(55-74)$ & 144 & 142 & NSCLC & PCR-RFLP \\
\hline Kaabachi & 2014 & Tunisia & Caucasians & $58.51 \pm 10.25$ & $52.64 \pm 6.36$ & 240 & 280 & Mixed & PCR-RFLP \\
\hline Kong & 2015 & China & Asians & $60(23-83)$ & $60(23-83)$ & 603 & 661 & NSCLC & PCR-TaqMan \\
\hline Liu & 2014 & China & Asians & $64 \pm 11$ & $63 \pm 11$ & 172 & 180 & ALC & PCR-RFLP \\
\hline Wei & 2014 & China & Asians & Mixed & Mixed & 500 & 200 & $\mathrm{SCC}$ & PCR-sequencing \\
\hline Maneechay & 2015 & Thailand & Asians & $62.8 \pm 11.7$ & $62.5 \pm 11.5$ & 113 & 113 & - & PCR-sequencing \\
\hline Hou & 2015 & China & Asians & Mixed & Mixed & 288 & 284 & $\mathrm{SCC}$ & PCR-RFLP \\
\hline $\mathrm{Bi}$ & 2016 & China & Asians & $51.29 \pm 5.82$ & $50.73 \pm 5.72$ & 50 & 50 & NSCLC & PCR-RFLP \\
\hline Çiçek & 2017 & Turkey & Caucasians & $60.41 \pm 11.42$ & $55.71 \pm 8.60$ & 59 & 55 & - & PCR-TaqMan \\
\hline $\mathrm{Wu}^{3}$ & 2016 & China & Asians & $57.4 \pm 5.8$ & $59.6 \pm 4.7$ & 426 & 445 & NSCLC & PCR-RFLP \\
\hline Gromowski & 2017 & Poland & Caucasians & $61(28-88)$ & $61(28-88)$ & 840 & 920 & - & PCR-TaqMan \\
\hline Yang & 2017 & China & Asians & $62.3 \pm 10.2$ & $63.0 \pm 10.3$ & 288 & 284 & $\mathrm{SCC}$ & PCR-RFLP \\
\hline $\mathrm{Ye}$ & 2018 & China & Asians & $18-60$ & $18-60$ & 800 & 500 & - & PCR \\
\hline
\end{tabular}

-, not applicable; ALC, adenocarcinoma; NSCLC, nonsmall-cell lung cancer; PCR-RFLP, polymerase chain reaction-restriction fragment length polymorphism; SCC, squamous cell carcinoma.

(AA vs. Aa+aa: $\mathrm{OR}=0.57,95 \% \mathrm{CI}=0.34-0.97, p=0.04$ ) in the random effect model (Fig. 2). However, no significant association was observed in Caucasians. Subgroup analysis by the cancer subtypes showed that Apal polymorphism was not associated with patients with NSCLC.

\section{Bsm1}

There were 10 case-control articles, including 3046 patients and 2716 controls. Our results showed that allele and genotypes of $B s m l$ had decreased lung cancer risk under each genetic comparison models (B vs. b: $\mathrm{OR}=0.59$, $95 \% \mathrm{CI}=0.45-0.78, p=0.0002 ; \mathrm{BB}$ vs. bb: $\mathrm{OR}=0.63$, $95 \% \mathrm{CI}=0.40-0.99, p=0.05 ; \mathrm{Bb}$ vs. bb: $\mathrm{OR}=0.53,95 \%$ $\mathrm{CI}=0.37-0.77, p=0.0007 ; \mathrm{BB}+\mathrm{Bb}$ vs. $\mathrm{bb}: \mathrm{OR}=0.52$, $95 \% \mathrm{CI}=0.36-0.74, p=0.0004 ; \mathrm{BB}$ vs. $\mathrm{Bb}+\mathrm{bb}: \mathrm{OR}=0.78$, $95 \% \mathrm{CI}=0.63-0.97, p=0.02$ ) as shown in Figure 3. Subgroup analysis by ethnicity suggested that Bsml polymorphism was a protective factor for decreasing lung cancer incidence in Asians (B vs. b: $\mathrm{OR}=0.45,95 \% \mathrm{CI}=0.35-0.58$, $p<0.00001 ; \mathrm{BB}+\mathrm{Bb}$ vs. bb: $\mathrm{OR}=0.39,95 \% \mathrm{CI}=0.32-0.46$, $p<0.00001$; $\mathrm{BB}$ vs. $\mathrm{Bb}+\mathrm{bb}: \mathrm{OR}=0.22,95 \% \mathrm{CI}=0.10-0.51$, $p=0.0004)$. This association was not detected in Caucasians. Subgroup analysis by the cancer subtypes indicated that Bsml polymorphism had significantly decreased the risk of patients with NSCLC (B vs. b: OR $=0.41,95 \%$ $\mathrm{CI}=0.29-0.58, p<0.00001 ; \mathrm{BB}+\mathrm{Bb}$ vs. $\mathrm{bb}: \mathrm{OR}=0.39,95 \%$ $\mathrm{CI}=0.31-0.49, p<0.00001 ; \mathrm{BB}$ vs. $\mathrm{Bb}+\mathrm{bb}: \mathrm{OR}=0.22$, $95 \% \mathrm{CI}=0.10-0.51, p=0.0004)$.

Fok1

Five articles were screened out, including 1362 patients and 1474 controls. No significant association was found between Fokl polymorphism and lung cancer risk under any genetic models ( $\mathrm{F}$ vs. f: $\mathrm{OR}=1.14,95 \% \mathrm{CI}=0.89-1.47$, $p=0.30$; FF vs. ff: $\mathrm{OR}=1.21,95 \% \mathrm{CI}=0.74-1.98, p=0.45$; Ff vs. ff: $\mathrm{OR}=0.88,95 \% \mathrm{CI}=0.53-1.47, p=0.63 ; \mathrm{FF}+\mathrm{Ff}$ vs. ff: $\mathrm{OR}=1.01,95 \% \mathrm{CI}=0.62-1.66, p=0.96$; $\mathrm{FF}$ vs. $\mathrm{Ff}+\mathrm{ff}$ : $\mathrm{OR}=1.33,95 \% \mathrm{CI}=0.98-1.80, p=0.07)$. Subgroup analysis by ethnicity indicated that Fokl polymorphism was associated with increased lung cancer risk in Asians ( $F$ vs. f: $\mathrm{OR}=1.59,95 \% \mathrm{CI}=1.25-2.03, p=0.0002 ; \mathrm{FF}+\mathrm{Ff}$ vs. ff: $\mathrm{OR}=1.93,95 \% \quad \mathrm{CI}=1.16-3.20, p=0.01 ; \mathrm{FF}$ vs. $\mathrm{Ff}+\mathrm{ff}$ : $\mathrm{OR}=1.76,95 \% \mathrm{CI}=1.27-2.45, p=0.0007)$. This association was not detected in Caucasians. Subgroup analysis by the cancer subtypes detected that FF genotype of Fok1 polymorphism increased the risk of patients with NSCLC (FF vs. $\mathrm{Ff}+\mathrm{ff}: \mathrm{OR}=1.59,95 \% \mathrm{CI}=1.02-2.49, p=0.04)$.

\section{Taq1}

Six articles contained 2204 patients, and 2369 controls were studied. The analysis showed that $\mathrm{T}$ allele and TT genotype were associated with increased cancer risk in the allelic model ( $\mathrm{T}$ vs. $\mathrm{t}$ : $\mathrm{OR}=1.14,95 \% \mathrm{CI}=1.02-1.27$, $p=0.02$ ) and the recessive model (TT vs. $\mathrm{Tt}+\mathrm{tt}: \mathrm{OR}=1.18$, 95\% CI $=1.02-1.37, p=0.02$ ) (Fig. 4). However, other genetic models did not reveal a significant association (TT vs. tt: $\mathrm{OR}=1.15,95 \% \mathrm{CI}=0.90-1.46, p=0.27 ; \mathrm{Tt}$ vs. $\mathrm{tt}$ : $\mathrm{OR}=1.20,95 \% \mathrm{CI}=0.95-1.52, p=0.13$; TT+Tt vs. $\mathrm{tt}:$ $\mathrm{OR}=1.17,95 \% \mathrm{CI}=0.93-1.47, p=0.17$ ). Subgroup analysis by ethnicity indicated that there was a significant relationship between $\mathrm{T}$ allele and TT genotype and lung cancer risk in Asians ( $\mathrm{T}$ vs. t: $\mathrm{OR}=1.56,95 \% \mathrm{CI}=1.12-2.17$, $p=0.008 ;$ TT vs. $\mathrm{T} t+\mathrm{tt}: \mathrm{OR}=1.60,95 \% \mathrm{CI}=1.12-2.28$, $p=0.009$ ), but not in Caucasians. Subgroup analysis by the cancer subtypes showed that $\mathrm{T}$ allele and $\mathrm{TT}$ genotype were risk factors for patient with NSCLC (T vs. t: OR $=1.40,95 \%$ $\mathrm{CI}=1.05-1.86, p=0.02 ; \mathrm{TT}$ vs. $\mathrm{Tt}+\mathrm{tt}: \mathrm{OR}=1.41,95 \%$ $\mathrm{CI}=1.04-1.93, p=0.03)$.

\section{$C d x 2$}

Two articles concerned the $C d x 2$ polymorphism; one was in Asians and one was in Caucasians. The result showed that TC and TT+TC genotype was associated with decreased lung cancer risk under heterozygous model (TC vs. $\mathrm{CC}$ : $\mathrm{OR}=0.81$, 95\% CI $=0.66-1.00, p=0.05)$ and dominant model (TT+TC vs. $\mathrm{CC}$ : $\mathrm{OR}=0.80,95 \% \mathrm{CI}=0.65-0.98, p=0.03$ ) analysis. Other genetic models showed no significant associations. 
Table 2. Meta-Analysis Results Between Genetic Polymorphisms of VDR and GC Genes and Lung Cancer Risk in Total Populations and Subgroup Analysis by Ethnicity and Lung Cancer Subtypes

\begin{tabular}{|c|c|c|c|c|c|c|c|}
\hline \multirow[b]{2}{*}{ SNPs } & \multirow[b]{2}{*}{ Genetic comparisons } & \multirow[b]{2}{*}{$\mathrm{n}$} & \multicolumn{2}{|c|}{ Test of association } & \multicolumn{3}{|c|}{ Test of heterogeneity } \\
\hline & & & OR $(95 \% C I)$ & $\mathrm{p}$ & $P h$ & $\mathrm{I}^{2}$ & Model \\
\hline \multicolumn{8}{|l|}{ Apal } \\
\hline \multirow[t]{5}{*}{ Total } & A vs. a & 10 & $0.83(0.66-1.03)$ & 0.09 & $<0.00001$ & $88 \%$ & $\mathrm{R}$ \\
\hline & AA vs. aa & & $0.74(0.51-1.07)$ & 0.11 & $<0.00001$ & $82 \%$ & $\mathrm{R}$ \\
\hline & Aa vs. aa & & $1.01(0.76-1.34)$ & 0.95 & $<0.00001$ & $80 \%$ & $\mathrm{R}$ \\
\hline & $\mathrm{AA}+\mathrm{Aa}$ vs. aa & & $0.88(0.68-1.14)$ & 0.34 & $<0.00001$ & $78 \%$ & $\mathrm{R}$ \\
\hline & AA vs. $\mathrm{Aa}+\mathrm{aa}$ & & $0.71(0.48,1.04)$ & 0.08 & $<0.00001$ & $88 \%$ & $\mathrm{R}$ \\
\hline \multirow[t]{3}{*}{ Caucasians } & A vs. a & 3 & $1.02(0.78-1.33)$ & 0.91 & 0.02 & $75 \%$ & $\mathrm{R}$ \\
\hline & $\mathrm{AA}+\mathrm{Aa}$ vs. aa & & $1.02(0.56-1.84)$ & 0.96 & 0.005 & $81 \%$ & $\mathrm{R}$ \\
\hline & AA vs. Aa+aa & & $1.09(0.91-1.30)$ & 0.36 & 0.27 & $23 \%$ & $\mathrm{~F}$ \\
\hline \multirow[t]{3}{*}{ Asians } & A vs. a & 7 & $0.74(0.55-1.00)$ & 0.05 & $<0.00001$ & $89 \%$ & $\mathrm{R}$ \\
\hline & $\mathrm{AA}+\mathrm{Aa}$ vs. aa & & $0.82(0.59-1.15)$ & 0.25 & $<0.0001$ & $82 \%$ & $\mathrm{R}$ \\
\hline & $\mathrm{AA}$ vs. $\mathrm{Aa}+\mathrm{aa}$ & & $0.57(0.34-0.97)$ & 0.04 & $<0.00001$ & $85 \%$ & $\mathrm{R}$ \\
\hline \multirow[t]{3}{*}{ NSCLC } & A vs. a & 5 & $0.93(0.79-1.10)$ & 0.41 & 0.08 & $52 \%$ & $\mathrm{R}$ \\
\hline & $\mathrm{AA}+\mathrm{Aa}$ vs. aa & & $0.98(0.70-1.38)$ & 0.91 & 0.002 & $77 \%$ & $\mathrm{R}$ \\
\hline & AA vs. Aa+aa & & $0.72(0.50-1.02)$ & 0.06 & 0.05 & $58 \%$ & $\mathrm{R}$ \\
\hline \multicolumn{8}{|c|}{$0.12(0.00-1.02)$} \\
\hline \multirow[t]{5}{*}{ Total } & B vs. b & 10 & $0.59(0.45-0.78)$ & 0.0002 & $<0.00001$ & $86 \%$ & $\mathrm{R}$ \\
\hline & BB vs. bb & & $0.63(0.40-0.99)$ & 0.05 & 0.06 & $50 \%$ & $\mathrm{R}$ \\
\hline & $\mathrm{Bb}$ vs. bb & & $0.53(0.37-0.77)$ & 0.0007 & $<0.00001$ & $86 \%$ & $\mathrm{R}$ \\
\hline & $\mathrm{BB}+\mathrm{Bb}$ vs. $\mathrm{bb}$ & & $0.52(0.36-0.74)$ & 0.0004 & $<0.00001$ & $86 \%$ & $\mathrm{R}$ \\
\hline & $\mathrm{BB}$ vs. $\mathrm{Bb}+\mathrm{bb}$ & & $0.78(0.63-0.97)$ & 0.02 & 0.11 & $42 \%$ & $\mathrm{~F}$ \\
\hline \multirow[t]{3}{*}{ Caucasians } & B vs. b & 4 & $0.94(0.84-1.06)$ & 0.32 & 0.40 & $0 \%$ & $\mathrm{~F}$ \\
\hline & $\mathrm{BB}+\mathrm{Bb}$ vs. bb & & $0.86(0.65-1.14)$ & 0.29 & 0.10 & $52 \%$ & $\mathrm{R}$ \\
\hline & $\mathrm{BB}$ vs. $\mathrm{Bb}+\mathrm{bb}$ & & $0.88(0.70-1.11)$ & 0.29 & 0.92 & $0 \%$ & $\mathrm{~F}$ \\
\hline \multirow[t]{3}{*}{ Asians } & B vs. b & 6 & $0.45(0.35-0.58)$ & $<0.00001$ & 0.05 & $55 \%$ & $\mathrm{R}$ \\
\hline & $\mathrm{BB}+\mathrm{Bb}$ vs. bb & & $0.39(0.32-0.46)$ & $<0.00001$ & 0.20 & $32 \%$ & $\mathrm{~F}$ \\
\hline & $\mathrm{BB}$ vs. $\mathrm{Bb}+\mathrm{bb}$ & & $0.22(0.10-0.51)$ & 0.0004 & 0.76 & $0 \%$ & $\mathrm{~F}$ \\
\hline \multirow[t]{3}{*}{ NSCLC } & B vs. b & 5 & $0.41(0.29-0.58)$ & $<0.00001$ & 0.06 & $56 \%$ & $\mathrm{R}$ \\
\hline & $\mathrm{BB}+\mathrm{Bb}$ vs. bb & & $0.39(0.31-0.49)$ & $<0.00001$ & 0.12 & $45 \%$ & $\mathrm{~F}$ \\
\hline & $\mathrm{BB}$ vs. $\mathrm{Bb}+\mathrm{bb}$ & & $0.22(0.10-0.51)$ & 0.0004 & 0.76 & $0 \%$ & $\mathrm{~F}$ \\
\hline \multicolumn{8}{|c|}{ (0.2) } \\
\hline Total & F vs. f & 5 & $1.14(0.89-1.47)$ & 0.30 & 0.009 & $70 \%$ & $\mathrm{R}$ \\
\hline & FF vs. ff & & $1.21(0.74-1.98)$ & 0.45 & 0.03 & $62 \%$ & $\mathrm{R}$ \\
\hline & Ff vs. ff & & $0.88(0.53-1.47)$ & 0.63 & 0.01 & $70 \%$ & $\mathrm{R}$ \\
\hline & $\mathrm{FF}+\mathrm{Ff}$ vs. ff & & $1.01(0.62-1.66)$ & 0.96 & 0.008 & $71 \%$ & $\mathrm{R}$ \\
\hline & $\mathrm{FF}$ vs. Ff+ff & & $1.33(0.98-1.80)$ & 0.07 & 0.06 & $55 \%$ & $\mathrm{R}$ \\
\hline Caucasians & F vs. f & 3 & $0.98(0.87-1.10)$ & 0.73 & 0.63 & $0 \%$ & $\mathrm{~F}$ \\
\hline & $\mathrm{FF}+\mathrm{Ff}$ vs. ff & & $0.72(0.44-1.16)$ & 0.17 & 0.09 & $58 \%$ & $\mathrm{R}$ \\
\hline & $\mathrm{FF}$ vs. Ff+ff & & $1.09(0.91-1.31)$ & 0.36 & 0.28 & $22 \%$ & $\mathrm{~F}$ \\
\hline Asians & F vs. f & 2 & $1.59(1.25-2.03)$ & 0.0002 & 0.68 & $0 \%$ & $\mathrm{~F}$ \\
\hline & $\mathrm{FF}+\mathrm{Ff}$ vs. ff & & $1.93(1.16-3.20)$ & 0.01 & 0.47 & $0 \%$ & $\mathrm{~F}$ \\
\hline & $\mathrm{FF}$ vs. $\mathrm{Ff}+\mathrm{ff}$ & & $1.76(1.27-2.45)$ & 0.0007 & 0.83 & $0 \%$ & $\mathrm{~F}$ \\
\hline NSCLC & F vs. f & 2 & $1.25(0.71-2.22)$ & 0.44 & 0.07 & $70 \%$ & $\mathrm{R}$ \\
\hline & $\mathrm{FF}+\mathrm{Ff}$ vs. ff & & $1.18(0.30-4.65)$ & 0.81 & 0.005 & $87 \%$ & $\mathrm{R}$ \\
\hline & $\mathrm{FF}$ vs. $\mathrm{Ff}+\mathrm{ff}$ & & $1.59(1.02-2.49)$ & 0.04 & 0.99 & $0 \%$ & $\mathrm{~F}$ \\
\hline Taq1 & & & & & & & \\
\hline Total & $\mathrm{T}$ vs. $\mathrm{t}$ & 6 & $1.14(1.02-1.27)$ & 0.02 & 0.12 & $42 \%$ & $\mathrm{~F}$ \\
\hline & TT vs. tt & & $1.15(0.90-1.46)$ & 0.27 & 0.13 & $41 \%$ & $\mathrm{~F}$ \\
\hline & $\mathrm{Tt}$ vs. $\mathrm{tt}$ & & $1.20(0.95-1.52)$ & 0.13 & 0.11 & $45 \%$ & $\mathrm{~F}$ \\
\hline & $\mathrm{TT}+\mathrm{Tt}$ vs. $\mathrm{tt}$ & & $1.17(0.93-1.47)$ & 0.17 & 0.79 & $0 \%$ & $\mathrm{~F}$ \\
\hline & $\mathrm{TT}$ vs. $\mathrm{Tt}+\mathrm{tt}$ & & $1.18(1.02-1.37)$ & 0.02 & 0.10 & $46 \%$ & $\mathrm{~F}$ \\
\hline Caucasians & $\mathrm{T}$ vs. $\mathrm{t}$ & 3 & $1.14(0.93-1.40)$ & 0.20 & 0.10 & $57 \%$ & $\mathrm{R}$ \\
\hline & TT+Tt vs. tt & & $1.17(0.92-1.47)$ & 0.20 & 0.51 & $0 \%$ & $\mathrm{~F}$ \\
\hline & TT vs. $\mathrm{Tt}+\mathrm{tt}$ & & $1.22(0.88-1.69)$ & 0.22 & 0.05 & $66 \%$ & $\mathrm{R}$ \\
\hline Asians & $\mathrm{T}$ vs. $\mathrm{t}$ & 3 & $1.56(1.12-2.17)$ & 0.008 & 0.99 & $0 \%$ & $\mathrm{~F}$ \\
\hline & $\mathrm{TT}+\mathrm{Tt}$ vs. $\mathrm{tt}$ & & $1.30(0.47-3.63)$ & 0.61 & 0.60 & $0 \%$ & $\mathrm{~F}$ \\
\hline & TT vs. $\mathrm{Tt}+\mathrm{tt}$ & & $1.60(1.12-2.28)$ & 0.009 & 0.98 & $0 \%$ & $\mathrm{~F}$ \\
\hline
\end{tabular}


TABle 2. (Continued)

\begin{tabular}{|c|c|c|c|c|c|c|c|}
\hline \multirow[b]{2}{*}{ SNPs } & \multirow[b]{2}{*}{ Genetic comparisons } & \multirow[b]{2}{*}{$\mathrm{n}$} & \multicolumn{2}{|c|}{ Test of association } & \multicolumn{3}{|c|}{ Test of heterogeneity } \\
\hline & & & OR $(95 \% C I)$ & $\mathrm{p}$ & $P h$ & $\mathrm{I}^{2}$ & Model \\
\hline \multirow[t]{3}{*}{ NSCLC } & $\mathrm{T}$ vs. $\mathrm{t}$ & 3 & $1.40(1.05-1.86)$ & 0.02 & 0.60 & $0 \%$ & $\mathrm{~F}$ \\
\hline & $\mathrm{TT}+\mathrm{Tt}$ vs. $\mathrm{tt}$ & & $1.45(0.62-3.41)$ & 0.39 & 0.58 & $0 \%$ & $\mathrm{~F}$ \\
\hline & $\mathrm{TT}$ vs. $\mathrm{Tt}+\mathrm{tt}$ & & $1.41(1.04-1.93)$ & 0.03 & 0.50 & $0 \%$ & $\mathrm{~F}$ \\
\hline \multicolumn{8}{|c|}{$1.41(1.04-1.00)$} \\
\hline \multirow[t]{5}{*}{ Total } & T vs. C & 2 & $0.91(0.70-1.17)$ & 0.45 & 0.07 & $70 \%$ & $\mathrm{R}$ \\
\hline & TT vs. CC & & $0.60(0.17-2.15)$ & 0.43 & 0.07 & $70 \%$ & $\mathrm{R}$ \\
\hline & TC vs. CC & & $0.81(0.66-1.00)$ & 0.05 & 0.77 & $0 \%$ & $\mathrm{~F}$ \\
\hline & $\mathrm{TT}+\mathrm{TC}$ vs. $\mathrm{CC}$ & & $0.80(0.65-0.98)$ & 0.03 & 0.99 & $0 \%$ & $\mathrm{~F}$ \\
\hline & TT vs. $\mathrm{TC}+\mathrm{CC}$ & & $0.70(0.16-3.04)$ & 0.63 & 0.03 & $80 \%$ & $\mathrm{R}$ \\
\hline \multicolumn{8}{|l|}{$G C(\operatorname{rs} 7041)$} \\
\hline \multirow[t]{5}{*}{ Total } & G vs. T & 3 & $0.90(0.65-1.25)$ & 0.52 & 0.003 & $83 \%$ & $\mathrm{R}$ \\
\hline & GG vs. TT & & $0.65(0.36-1.19)$ & 0.17 & 0.07 & $63 \%$ & $\mathrm{R}$ \\
\hline & GT vs. TT & & $0.97(0.56-1.70)$ & 0.93 & 0.0001 & $89 \%$ & $\mathrm{R}$ \\
\hline & GG+GT vs. TT & & $0.93(0.55-1.59)$ & 0.80 & 0.0002 & $88 \%$ & $\mathrm{R}$ \\
\hline & $\mathrm{GG}$ vs. $\mathrm{GT}+\mathrm{TT}$ & & $0.67(0.40-1.11)$ & 0.12 & 0.12 & $52 \%$ & $\mathrm{R}$ \\
\hline \multirow[t]{3}{*}{ NSCLC } & $\mathrm{G}$ vs. $\mathrm{T}$ & 2 & $0.76(0.62-0.92)$ & 0.004 & 0.14 & $53 \%$ & $\mathrm{R}$ \\
\hline & GG+GT vs. TT & & $0.72(0.47-1.12)$ & 0.15 & 0.01 & $84 \%$ & $\mathrm{R}$ \\
\hline & GG vs. GT+TT & & $0.58(0.35-0.95)$ & 0.03 & 0.15 & $51 \%$ & $\mathrm{R}$ \\
\hline \multicolumn{8}{|l|}{$G C(\mathrm{rs} 4588)$} \\
\hline \multirow[t]{5}{*}{ Total } & A vs. C & 2 & $0.89(0.73-1.07)$ & 0.21 & 0.46 & $0 \%$ & $\mathrm{~F}$ \\
\hline & AA vs. CC & & $0.70(0.42-1.14)$ & 0.15 & 0.77 & $0 \%$ & $\mathrm{~F}$ \\
\hline & $\mathrm{AC}$ vs. $\mathrm{CC}$ & & $0.94(0.74-1.21)$ & 0.64 & 0.33 & $0 \%$ & $\mathrm{~F}$ \\
\hline & $\mathrm{AA}+\mathrm{AC}$ vs. $\mathrm{CC}$ & & $0.90(0.71-1.14)$ & 0.39 & 0.36 & $0 \%$ & $\mathrm{~F}$ \\
\hline & $\mathrm{AA}$ vs. $\mathrm{AC}+\mathrm{CC}$ & & $0.71(0.44-1.15)$ & 0.16 & 0.90 & $0 \%$ & $\mathrm{~F}$ \\
\hline
\end{tabular}

95\% CI, 95\% confidence interval; F, fixed-effect model; n, number of included studies; OR, odds ratio; Ph, $p$-value of heterogeneity; R, random-effect model; SNP, single nucleotide polymorphism.

\section{Association of GC polymorphisms in lung cancer risk}

rs7041. Three articles contained 1142 patients, and 1219 controls were studied. The analysis showed that rs7041 polymorphism of $G C$ gene was not associated with lung cancer risk $(\mathrm{G}$ vs. $\mathrm{T}$ : $\mathrm{OR}=0.90,95 \% \mathrm{CI}=0.65-1.25$, $p=0.52 ; \mathrm{GG}$ vs. TT: $\mathrm{OR}=0.65,95 \% \mathrm{CI}=0.36-1.19$, $p=0.17$; GT vs. TT: $\mathrm{OR}=0.97,95 \% \mathrm{CI}=0.56-1.70$, $p=0.93 ; \mathrm{GG}+\mathrm{GT}$ vs. TT: $\mathrm{OR}=0.93,95 \% \mathrm{CI}=0.55-1.59$, $p=0.80$; GG vs. GT+TT: $\mathrm{OR}=0.67,95 \% \mathrm{CI}=0.40-1.11$, $p=0.12$ ). Subgroup analysis by the cancer subtypes showed that $\mathrm{G}$ allele and $\mathrm{GG}$ genotype might be protective factors for Chinese patients with NSCLC (G vs. T: OR $=0.76,95 \%$ $\mathrm{CI}=0.62-0.92, p=0.004 ; \mathrm{GG}$ vs. $\mathrm{GT}+\mathrm{TT}: \mathrm{OR}=0.58,95 \%$ $\mathrm{CI}=0.35-0.95, p=0.03)$. rs4588. Two articles were included for analysis. We did not detect a link between this genetic polymorphism and lung cancer risk under any of the genetic models (Table 2).

\section{Interaction of VDR polymorphisms and smoking status/gender in lung cancer risk}

Five articles that concerned the interaction between $V D R$ Apal, Bsm1, or Taq1 polymorphisms and smoking status in lung cancer risk were analyzed. Based on the given data, it showed that the interaction of TT genotype of Taql and smoking was associated with increased lung cancer risk (TT vs. $\mathrm{Tt}+\mathrm{tt}$ : $\mathrm{OR}=2.41,95 \% \mathrm{CI}=1.53-3.81, p=0.0002$ ). However, interaction between other two SNPs and smoking was not associated with the lung cancer incidence (AA+Aa

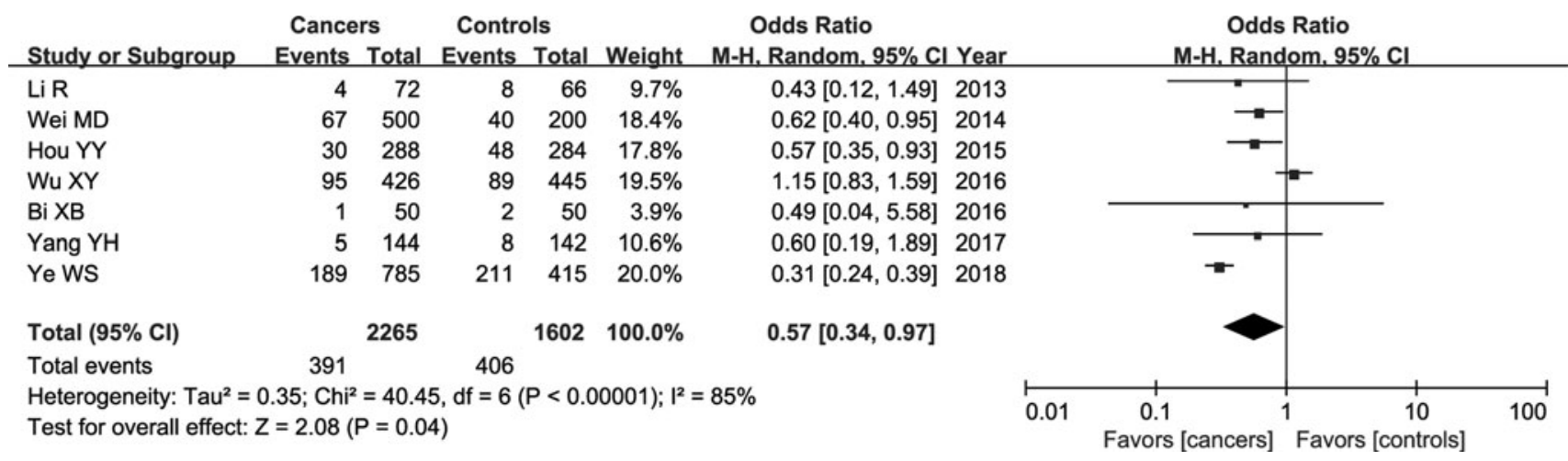

FIG. 2. Association between lung cancer risk and recessive genetic model of Apal polymorphism in Asian populations. 


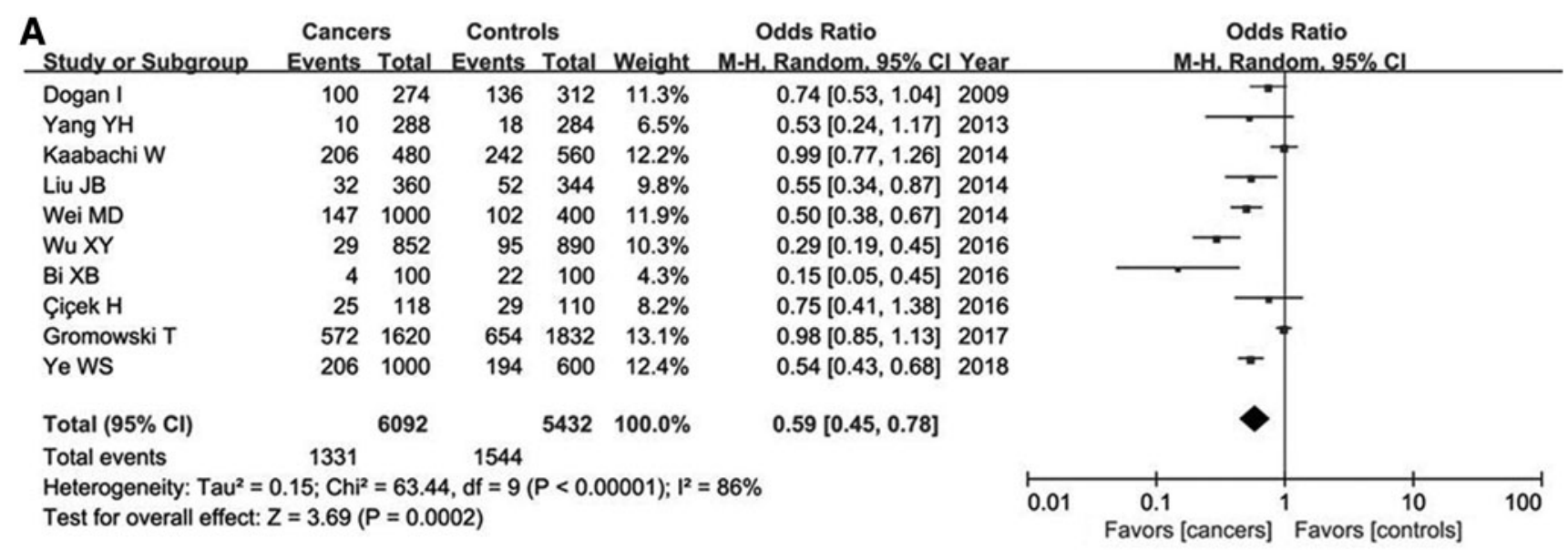

\begin{tabular}{|c|c|c|c|c|c|}
\hline B & Cancer & & Contro & & \\
\hline Study or Subgroup & Events & Total & Events & Total & Weight \\
\hline Dogan I & 20 & 77 & 25 & 70 & $19.3 \%$ \\
\hline Yang YH & 0 & 134 & 0 & 124 & \\
\hline Wei MD & 0 & 353 & 0 & 98 & \\
\hline Kaabachi W & 40 & 114 & 46 & 130 & $24.4 \%$ \\
\hline Liu JB & 0 & 148 & 5 & 130 & $2.3 \%$ \\
\hline Çiçek H & 3 & 40 & 3 & 32 & $6.0 \%$ \\
\hline Wu XY & 6 & 409 & 23 & 396 & $14.7 \%$ \\
\hline $\mathrm{Bi}$ XB & 0 & 46 & 2 & 32 & $2.0 \%$ \\
\hline Gromowski T & 92 & 422 & 122 & 506 & $31.3 \%$ \\
\hline YeWS & 0 & 294 & 0 & 106 & \\
\hline Total (95\% Cl) & & 2037 & & 1624 & $100.0 \%$ \\
\hline Total events & 161 & & 226 & & \\
\hline $\begin{array}{l}\text { Heterogeneity: } \mathrm{Tau}^{2}= \\
\text { Test for overall effect }\end{array}$ & $\begin{array}{l}.14 ; C^{2} i^{2} \\
=1.98(F\end{array}$ & $\begin{array}{l}=11.92 \\
=0.05\end{array}$ & 5) $d f=6$ ( & $P=0.0$ & $6) ; 1^{2}=$ \\
\hline
\end{tabular}

Odds Ratio

Random. $95 \%$ CI Year

$0.63[0.31,1.28] 2009$

Not estimable 2013

Not estimable 2014

$0.99[0.58,1.67] 2014$

$0.08[0.00,1.40] 2014$

$0.78[0.15,4.17] 2016$

$0.24[0.10,0.60] 2016$

$0.13[0.01,2.83] 2016$

$0.88[0.64,1.19] 2017$

Not estimable 2018

$0.63[0.40,0.99]$

\section{C}

Study or Subgroup Events Total Events Total Weight M-H. Random, 95\% Cl Year

\begin{tabular}{llllllll}
\hline Dogan I & 60 & 117 & 86 & 131 & $10.4 \%$ & $0.55[0.33,0.92] 2009$
\end{tabular}

Yang YH

Kaabachi W

Liu JB

Wei MD

WuXY

Bi XB

Çiçek H

Gromowski T

YeWS

Total $(95 \% \mathrm{Cl})$

Total events

$\begin{array}{lllll}10 & 144 & 18 & 142 & 8.0 \%\end{array}$

$\begin{array}{lllll}126 & 200 & 150 & 234 & 11.3 \%\end{array}$

$\begin{array}{lllll}32 & 180 & 42 & 167 & 10.3 \%\end{array}$

$\begin{array}{lllll}147 & 500 & 102 & 200 & 11.7 \%\end{array}$

$\begin{array}{lllll}17 & 420 & 49 & 422 & 9.9 \%\end{array}$

$\begin{array}{rrrrr}4 & 50 & 18 & 48 & 5.6 \% \\ 19 & 56 & 23 & 52 & 8.2 \%\end{array}$

$\begin{array}{lllll}3888 & 718 & 410 & 794 & 12.5 \%\end{array}$

Heterogeneity: $\mathrm{Tau}^{2}=0.27 ; \mathrm{Chi}^{2}=62.81, \mathrm{df}=9(\mathrm{P}<0.00001) ; \mathrm{I}^{2}=86 \%$

Test for overall effect: $Z=3.38(P=0.0007)$

0.5110 .2

$0.95[0.64,1.41] 2014$

$0.64[0.38,1.08] 2014$

$0.40[0.29,0.56] 2014$

$0.32[0.18,0.57] 2016$

$0.14[0.04,0.47] 2016$

$0.65[0.30,1.41] 2016$

$1.10[0.90,1.35] 2017$

$0.38[0.28,0.51] 2018$

$0.53[0.37,0.77]$

FIG. 3. Association between lung cancer risk and Bsml polymorphism under the allelic model (A), homozygous model (B), heterozygous model (C), dominant model (D), and recessive model (E).

vs. aa: $\mathrm{OR}=0.87,95 \% \mathrm{CI}=0.50-1.49, p=0.60 ; \mathrm{BB}$ vs. $\mathrm{Bb}+\mathrm{bb}: \mathrm{OR}=2.11,95 \% \mathrm{CI}=0.18-24.92, p=0.55)$.

Two articles that concerned the interaction between $V D R$ Apal polymorphism and gender in lung cancer risk were included for studying. The statistical analysis showed that AA+Aa genotype was associated with decreased lung cancer risk in males (AA+Aa vs. aa: $\mathrm{OR}=0.48,95 \% \mathrm{CI}=0.28-0.82$, $p=0.007$ ), while this protective relationship was not found in female patients (AA+Aa vs. aa: $\mathrm{OR}=0.64,95 \% \mathrm{CI}=0.15$ 2.77, $p=0.55)$.

\section{Sensitivity analysis and publication bias}

A sensitivity analysis was subsequently conducted to assess whether our results were substantially influenced by one individual study. At each time, we deleted one included case- 


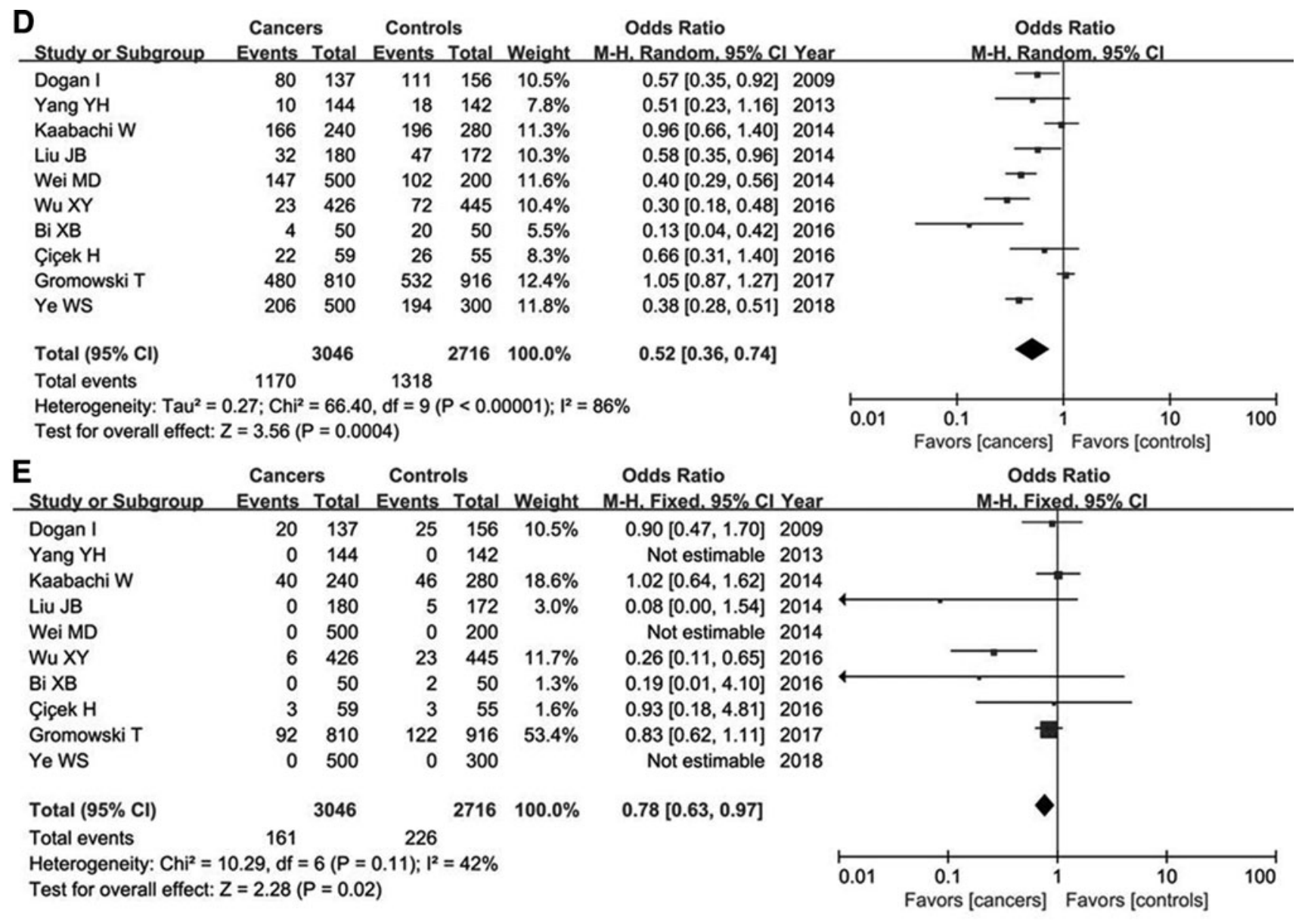

FIG. 3. (Continued).

control study to recalculate the significance of the results, and the obtained results showed that the ORs were not significantly changed. The funnel plot was used to evaluate the publication bias. The shape of the funnel plot was relatively symmetrical, which indicated that no publication bias existed in this meta-analysis (Fig. 5).

\section{Discussion}

In the present meta-analysis, 15 case-control articles were included. The results showed that $B s m 1$ and $C d x 2$ polymorphisms were protective factors for avoiding lung cancer incidence, while T allele and TT genotype of Taql were risk factors for lung cancer susceptibility. Our results were partly consistent with previous meta-analysis studies conducted by Yu et al. (2018), which indicated that the Bsml A allele was negatively related to the lung cancer risk and the $\mathrm{T}$ allele carriers were at increased risk of lung cancer, and by Li et al. (2019), which suggested that Bsm1, Taq1, and $C d x$-2 polymorphisms may contribute to lung cancer susceptibility.

Vitamin D may play a beneficial role in pulmonary inflammation and may control lung cancer by favorably altering the lung tumor microenvironment and immune function (Prietl et al., 2013). Evidences have suggested that vitamin D metabolites exhibit chemopreventive, antiproliferative, and antimetastatic activity in preclinical models of lung cancer
(Shaurova et al., 2018). Variations in vitamin D may influence the status of vitamin D and its functions, in turn, affecting disease progression. However, epidemiologic studies exploring the relationship between the polymorphisms of genes involved in vitamin D system and lung cancer risk have showed conflicting results. Therefore, we conducted the present meta-analysis.

VDR expresses in many tissues and is detectable in the lung carcinogenesis spectrum (Menezes et al., 2008). Increased VDR expression in lung adenocarcinoma is associated with improved survival (Kim et al., 2012). Besides, nuclear VDR status might be a prognostic marker in NSCLC (Srinivasan et al., 2011). SNPs in the VDR gene potentially influence the binding of 1,25(OH)2D. Haznadar et al. (2016) found that four SNPs in VDR are involved in regulation of vitamin D3 expression in the controls: the alleles, which are associated with increased cancer risk, are also associated with decreased vitamin D levels and vice versa, suggesting their functional significance in the context of lung cancer. VDR gene is significantly associated with lung cancer status by affecting target mRNA expression and modulating vitamin D3 levels (Haznadar et al., 2018). Heist et al. (2008) showed that the T allele of the VDR Fokl polymorphism and the G-T$\mathrm{C}(C d x-2-F o k 1-B s m 1)$ haplotype were associated with worse survival of NSCLC. An effect of Apal polymorphisms of the $V D R$ gene on the chemotherapy response in patients with 


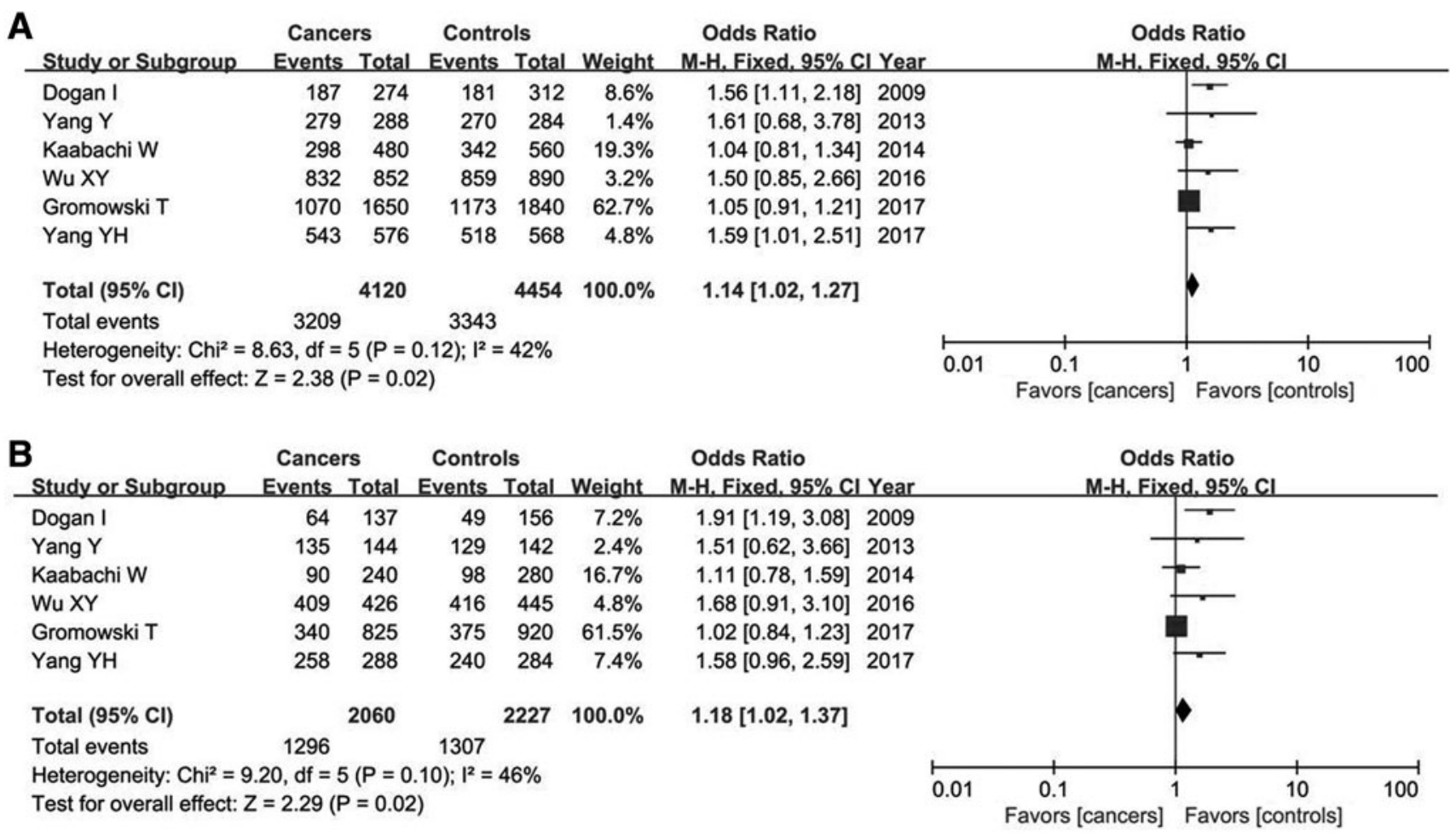

FIG. 4. Association between lung cancer risk and Taq1 polymorphism under the allelic model (A) and recessive model (B).

NSCLC has also been identified, as well as a prognostic role of the VDR gene polymorphisms in Chinese patients with advanced NSCLC (Xiong et al., 2013).

$G C$ has immunomodulatory functions in lung, predominantly relating to macrophage activation and neutrophil chemotaxis (Chun, 2012). The majority of circulating vitamin $\mathrm{D}$ is bound with DBP, and its uptake into cells occurs in both bound and unbound forms, suggesting the significant roles of DBP as well (Chishimba et al., 2010). Gene polymorphisms in the $G C$ gene are associated with the expression levels of 25(OH)D (Palosaari et al., 2003). Variations within GC gene may alter the protein function, and result in airway diseases, implying a vital role of $G C$ in prevention of diseases.
In China, lung cancer still ranks first and is the leading cause of death from malignant tumors. Its incidence has grown rapidly, especially among the younger generation, contributing to heavy disease burden. According to the National Central Cancer Registry of China, there were approximately 782,000 estimated new cases of lung cancer and 626,000 estimated deaths in China in 2014 (Chen et al., 2018). Due to the late-stage diagnosis of lung cancer in most of the patients, the 5-year survival for this disease is $16.1 \%$. Lung cancer molecular epidemiology studies in China suggest that lung cancer targeted genes might have very important roles in diagnosis and treatment of the cancer diseases (Zhou, 2014). In present study, subgroup

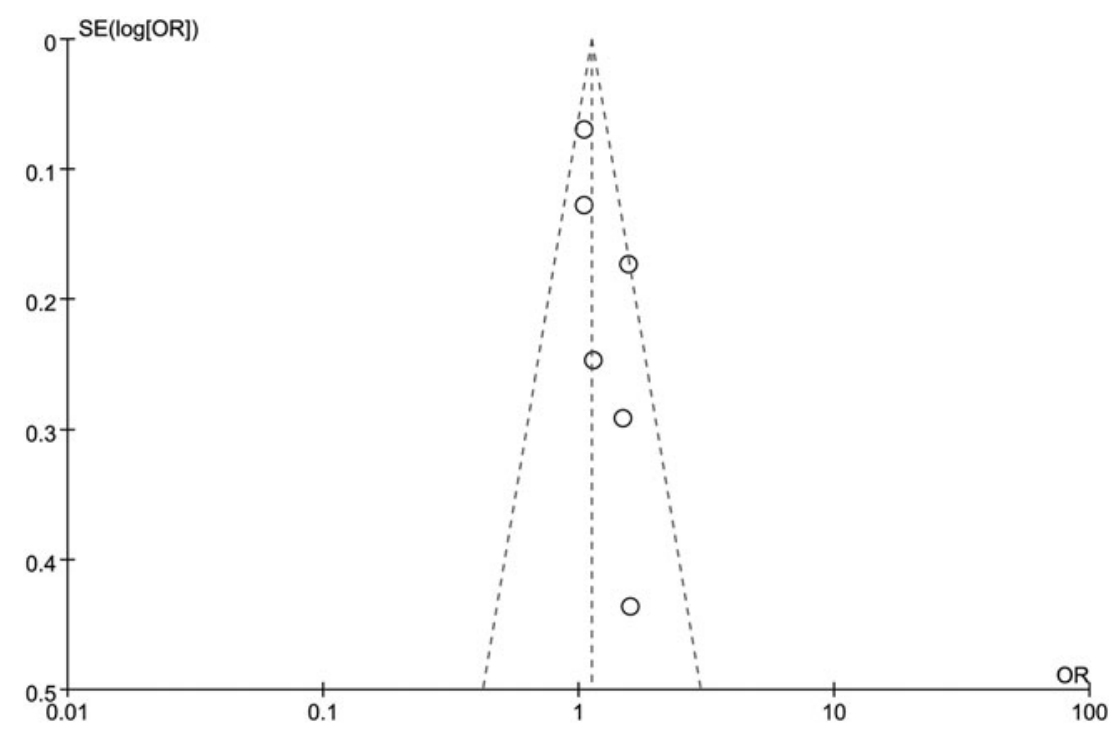

FIG. 5. Funnel plot of the association between allelic model of Taq1 polymorphism and lung cancer risk. 
analysis showed that AA genotype of Apal and B allele and BB genotypes of $B s m 1$ polymorphisms were protective factors in Chinese population, while Fokl and Taq1 polymorphisms were risk factors in Chinese population. This result provides a new insight in lung cancer prognosis in Chinese population.

Several limitations were presented in the present metaanalysis. First, the number of included case-control studies for such SNPs was limited. Second, although several included articles considered the combined genotypes or haplotypes in lung cancer risk, the data couldn't be extracted, so we didn't conduct the statistical analysis. Third, the stratification analysis according to lung cancer stage might provide great significance in diagnosis and treatment; however, only two articles were considered. Finally, the interaction between genetics and other risk factors such as vitamin D concentrations should be further considered.

In conclusion, our results suggested that Bsm1 and $C d x 2$ polymorphisms were associated with decreased lung cancer risk, and T allele and TT genotype of Taql were linked to increased cancer risk. In addition, AA genotypes of Apal and $B s m 1$ variants were protective factors in Asian populations; and Fokl and Taql were risk factors in Asian populations. However, future well-designed case-control studies with large populations and more ethnicities are still required to deeply calculate the association.

\section{Author Disclosure Statement}

No competing financial interests exist.

\section{Funding Information}

This work was supported by Weifang Medical University and Weifang People's Hospital, Weifang, China.

\section{References}

Bi X, Jia Y, Liu W, et al. (2016) Vitamin D receptor gene polymorphism and genetic susceptibility of non-small cell lung cancer. J Trop Med 16:905-908.

Bossé Y, Amos CI (2018) A decade of GWAS results in lung cancer. Cancer Epidemiol Biomarkers Prev 27:363379.

Bouillon R, Pauwels S (2018) The vitamin D-binding protein. In: Feldman D (ed.). Vitamin D. Amsterdam, Netherlands: Elsevier, pp 97-115.

Carlberg C, Campbell MJ (2013) Vitamin D receptor signaling mechanisms: integrated actions of a well-defined transcription factor. Steroids 78:127-136.

Carlberg C, Seuter S, Heikkinen S (2012) The first genomewide view of vitamin $\mathrm{D}$ receptor locations and their mechanistic implications. Anticancer Res 32:271-282.

Chen W, Sun K, Zheng R, et al. (2018) Cancer incidence and mortality in China, 2014. Chin J Cancer Res 30:1.

Chishimba L, Thickett D, Stockley R, Wood A (2010) The vitamin $\mathrm{D}$ axis in the lung: a key role for vitamin D-binding protein. Thorax 65:456-462.

Chun RF (2012) New perspectives on the vitamin D binding protein. Cell Biochem Funct 30:445-456.

Çiçek H, Güleken N, Öztuzcu S, Sevinç A (2017) Vitamin D receptor polymorphisms and related biochemical parameters in various cancer species. Turk J Biochem 42:161-168.
Cooke NE, Willard H, David E, George DL (1986) Direct regional assignment of the gene for vitamin $\mathrm{D}$ binding protein (Gc-globulin) to human chromosome 4q11-q13 and identification of an associated DNA polymorphism. Hum Genet 73: 225-229.

de Groot PM, Wu CC, Carter BW, Munden RF (2018) The epidemiology of lung cancer. Transl Lung Cancer Res 7:220.

Delanghe JR, Speeckaert R, Speeckaert MM (2015) Behind the scenes of vitamin $\mathrm{D}$ binding protein: more than vitamin $\mathrm{D}$ binding. Best Pract Res Clin Endocrinol Metab 29:773-786.

DeLuca HF (2012) Vitamin D: Metabolism and Function. Heidelberg, Germany: Springer Science \& Business Media.

Dogan I, Onen HI, Yurdakul AS, et al. (2009) Polymorphisms in the vitamin $\mathrm{D}$ receptor gene and risk of lung cancer. Med Sci Monit 15:BR232-BR242.

Dougall AL (2019) 104 Cancer: lung. In: Cambridge Handbook of Psychology, Health and Medicine. Cambridge, United Kingdom: Cambridge University Press, pp 444.

Duruisseaux M, Esteller M (2018) Lung cancer epigenetics: from knowledge to applications. Semin Cancer Bio 51:116128.

Esposito L, Conti D, Ailavajhala R, Khalil N, et al. (2010) Lung cancer: are we up to the challenge? Curr Genom 11:513.

Fu L, Borges CR, Rehder DS, et al. (2016) Characterization of additional vitamin D binding protein variants. J Steroid Biochem Mol Biol 159:54-59.

Fu Y, Li J, Zhang Y (2014) Polymorphisms in the vitamin D receptor gene and the lung cancer risk. Tumor Biol 35:13231330.

Goldstraw P, Crowley J, Chansky K, et al. (2007) The IASLC Lung Cancer Staging Project: proposals for the revision of the TNM stage groupings in the forthcoming (seventh) edition of the TNM classification of malignant tumours. J Thorac Oncol 2:706-714.

Goltzman D, Hendy GN, White JH (2015) Vitamin D and its receptor during late development. Biochim Biophys Acta 1849:171-180.

Gromowski T, Gapska P, Scott RJ, et al. (2017) Serum 25 (OH) D concentration, common variants of the VDR gene and lung cancer occurrence. Int J Cancer 141;336-341.

Haussler MR, Whitfield GK, Kaneko I, et al. (2013) Molecular mechanisms of vitamin D action. Calcif Tissue Int 92:77-98.

Haznadar M, Krausz KW, Margono E, et al. (2016) Circulating vitamin D2 and D3 levels and single nucleotide polymorphism associations with lung cancer status: a case-control study. Cancer Res 76(14 supplement):4320.

Haznadar M, Krausz KW, Margono E, et al. (2018) Inverse association of vitamin D3 levels with lung cancer mediated by genetic variation. Cancer Med 7:2764-2775.

Heist RS, Zhou W, Wang Z, et al. (2008) Circulating 25hydroxyvitamin D, VDR polymorphisms, and survival in advanced non-small-cell lung cancer. J Clin Oncol 26:5596-5602.

Hou Y (2015) Relationship of vitamin D receptor gene polymorphisms with susceptibility, chemotherapeutic effect and prognosis of squamous cell carcinoma of lung [Master's degree]. Chengde Medical College. Available at: http://kns.cnki .net/KCMS/detail/detail.aspx dbcode=CMFD\&dbname=CMF D201601\&filename $=1015719072$. nh\&uid $=$ WEEvREcwSIJHS ldRa1FhdXNzY2Z1UlZvOGJ1Y2F3bXdQekhJZWF0bWJzV $\mathrm{T} 0=\$ 9 A 4 h F \_Y A u v Q 5 o b g V A q N K P C Y c E j K e n s W 4 I Q M o v w$ HtwkF4VYPoHbKxJw!!\&v=MjQ3OTk4ZVgxTHV4WVM3 RGgxVDNxVHJXTTFGckNVUjdxZlpPVnVGQ3ZsV3JyQ VZGMjZHN1M1RjIITHJaRWJQSVI= $($ accessed May 28, 2015). 
Jeon S-M, Shin E-A (2018) Exploring vitamin D metabolism and function in cancer. Exp Mol Med 50:20.

Kaabachi W, Kaabachi S, Rafrafi A, et al. (2014) Association of vitamin D receptor FokI and ApaI polymorphisms with lung cancer risk in Tunisian population. Mol Biol Rep 41:65456553.

Kim SH, Chen G, King AN, et al. (2012) Characterization of vitamin D receptor (VDR) in lung adenocarcinoma. Lung Cancer 77:265-271.

Koinis F, Kotsakis A, Georgoulias V (2016) Small cell lung cancer (SCLC): no treatment advances in recent years. Transl Lung Cancer Res 5:39.

Kong J, Xu F, Qu J, et al. (2015) Genetic polymorphisms in the vitamin D pathway in relation to lung cancer risk and survival. Oncotarget 6:2573.

Laing CJ, Cooke NE (2005) Vitamin D-binding protein. In: Feldman D (ed.). Vitamin D. Amsterdam, Netherlands: Elsevier, pp 117-134.

Lemjabbar-Alaoui $\mathrm{H}$, Hassan OU, Yang Y-W, Buchanan P (2015) Lung cancer: biology and treatment options. Biochim Biophys Acta 1856:189-210.

Lerner L, Winn R, Hulbert A (2018) Lung cancer early detection and health disparities: the intersection of epigenetics and ethnicity. J Thorac Dis 10:2498-2507.

Li M, Liu X, Liu N, et al. (2019) Association between polymorphisms of vitamin $\mathrm{D}$ receptor and lung cancer susceptibility: evidence from an updated meta-analysis. J Cancer 10: 3639-3649.

Li R, Lou Y, Yan B, et al. (2013) Relationship between vitamin $\mathrm{D}$ receptor gene rs7975232 single nucleotide polymorphism and lung cancer. Chin Med 8:1390-1392.

Liu J, Hou Y, Qi X, Yang Y (2014) Relationship between gene polymorphisms of vitamin D receptor and susceptibility of lung adenocarcinoma. Hebei Med J 36:1780-1782.

Liu Y, Chen W, Hu ZB, et al. (2011) Plasma vitamin D levels and vitamin $\mathrm{D}$ receptor polymorphisms are associated with survival of non-small cell lung cancer. Chin J Cancer Res 23: 33-37.

Malhotra J, Malvezzi M, Negri E, et al. (2016) Risk factors for lung cancer worldwide. Eur Respir J 48:889-902.

Maneechay W, Boonpipattanapong T, Kanngurn S, et al. (2015) Single nucleotide polymorphisms in the GC gene for vitamin $\mathrm{D}$ binding protein in common cancers in Thailand. Asian Pac J Cancer Prev 16:3339-3344.

Mao Y, Yang D, He J, Krasna MJ (2016) Epidemiology of lung cancer. Surg Oncol Clin 25:439-445.

Menezes RJ, Cheney RT, Husain A, et al. (2008) Vitamin D receptor expression in normal, premalignant, and malignant human lung tissue. Cancer Epidemiol Biomarkers Prev 17: 1104-1110.

Palosaari H, Parisien JP, Rodriguez JJ, et al. (2003) STAT protein interference and suppression of cytokine signal transduction by measles virus $\mathrm{V}$ protein. J Virol 77:76357644.

Prietl B, Treiber G, Pieber T, Amrein K (2013) Vitamin D and immune function. Nutrients 5:2502-2521.

Schwartz AG, Cote ML (2016) Epidemiology of lung cancer. In: Ahmad S, Gadgeel S (eds.). Lung Cancer and Personalized Medicine. Cham, Switzerland: Springer, pp 21-41.

Shaurova T, Seshadri M, Hershberger PA (2018) Vitamin D and lung cancer. In: Feldman D (ed.). Vitamin D. Amsterdam, Netherlands: Elsevier, pp 875-890.

Siegel RL, Miller KD, Jemal A (2019) Cancer statistics, 2019. CA Cancer J Clin 69:7-34.
Sinotte M, Diorio C, Berube S, et al. (2008) Genetic polymorphisms of the vitamin $\mathrm{D}$ binding protein and plasma concentrations of 25-hydroxyvitamin $\mathrm{D}$ in premenopausal women. Am J Clin Nutr 89:634-640.

Srinivasan M, Parwani AV, Hershberger PA, et al. (2011) Nuclear vitamin D receptor expression is associated with improved survival in non-small cell lung cancer. J Steroid Biochem Mol Biol 123:30-36.

Torre LA, Siegel RL, Jemal A (2016) Lung cancer statistics. In: Ahmad A, Gadgeel S (eds.). Lung Cancer and Personalized Medicine. Cham, Switzerland: Springer, pp 1-19.

Travis WD, Brambilla E, Burke AP, et al. (2015) WHO classification of tumours of the lung, pleura. Thymus Heart 4: 78-79.

Vijayvergia N, Shah PC, Denlinger CS (2015) Survivorship in non-small cell lung cancer: challenges faced and steps forward. J Natl Compr Canc Netw 13:1151-1161.

Wei M, Su G, Ling Z, Wei S (2014) Clinical study effection of vitamin $\mathrm{D}$ receptor gene polymorphism on the susceptibility of lung squamous cell carcinoma, and chemotherapy curative. Chronic Pathematol J 15:349-351.

Wensheng Y, Chen G, Pan D, et al. (2018) Clinical value of vitamin $\mathrm{D}$ receptor gene polymorphism in lung cancer screening. Chin J Prim Med Pharm 25:2320-2323.

Wilson RT, Bortner JD Jr., Roff A, et al. (2015) Genetic and environmental influences on plasma vitamin $\mathrm{D}$ binding protein concentrations. Transl Res 165:667-676.

Wu X, Cheng J, Yang K (2016) Vitamin D-related gene polymorphisms, plasma 25-hydroxy-vitamin $\mathrm{D}$, cigarette smoke and non-small cell lung cancer (NSCLC) risk. Int J Mol Sci 17:1597.

Xiong L, Cheng J, Gao J, et al. (2013) Vitamin D receptor genetic variants are associated with chemotherapy response and prognosis in patients with advanced non-small-cell lung cancer. Clin Lung Cancer 14:433-439.

Yang Y, Wu J, Zhou W, et al. (2017) Association of vitamin D receptor gene Apa1 and Taq1 polymorphisms with susceptibility to lung squamous cell carcinoma. J Hebei Med Univ 38: 20-23.

Yang Y, Zhou W, Tang L, et al. (2013) The effect of interaction of VDR polymorphisms and smoking on lung cancer risk. Chin J Gerontol 33:3844-3846.

Ye W, Chen G, Pan DH, et al. (2018) Clinical value of vitamin $\mathrm{D}$ receptor gene polymorphism in lung cancer screening. Chin J Prim Med Pharm 18:2320-2323.

Yu Z-H, Chen M, Zhang Q-Q, Hu X (2018) The association of vitamin $\mathrm{D}$ receptor gene polymorphism with lung cancer risk: an update meta-analysis. Comb Chem High Throughput Screen 21:704-710.

Zhong H, Zhou R, Feng Y, et al. (2014) Association of vitamin $\mathrm{D}$ receptor gene polymorphism with the risk of lung cancer: a meta-analysis. J Recept Signal Transduct Res 34:500-505.

Zhou C (2014) Lung cancer molecular epidemiology in China: recent trends. Transl Lung Cancer Res 3:270.

Address correspondence to: Wei Tan, MD

Postgraduate Department of Internal Medicine Weifang Medical University Weifang 261053

China

E-mail: tanwei201600@163.com 